Bangladesh J. Sci. Res. 26(1\&2): 61-73, 2013 (December)

\title{
IMPACT OF DECISION-MAKING POWER INDEX ON FERTILITY BEHAVIOR AMONG WOMEN OF DIFFERENT AGE COHORTS IN BANGLADESH
}

\author{
Naznin Alam*1 , M. Ershadul Haque, Nahid Sultana Sumi and Md. Akhtar Hossain \\ Department of Statistics, Biostatistics \& Informatics, University of Dhaka, \\ Dhaka - 1000, Bangladesh
}

\begin{abstract}
Utilizing the 2007 BDHS data, this study examined the differential effect of decisionmaking power index on the use of contraception across different age cohorts of women. The findings indicated more pronounced impact of women's decision making power to increase contraception use aged above 25 than below 25 aged women. This implies more needs of promoting decision making power among the younger women (below 25) than the older women (above 25) for the betterment of family planning. However, decision making power did not show significant influence on decision of stopping women's childbearing in any of the younger and older women cohorts.
\end{abstract}

Key words: Decision making power, fertility behavior, contraception uses, childbearing, women cohorts, Bangladesh

\section{Introduction}

Women's empowerment has been recognized as important to their access to reproductive health services, including family planning since the 1994 International Conference on Population and Development. Women's lack of power restricts their ability to make decisions about family planning practice, as well as to have an open discussion with their partners about it (Blanc 2001, Mai and Kurimoto 2012).

Egyptian women, having freedom of movement, having at least some control in household matters and budget decisions, and being involved in family planning decision making were all positively related to current use of contraceptives (Govindasamy and Malhotra 1996). In a study of 18 developing countries, Bankole and Singh (1998) determined that the use of modern contraceptives was highest when both partners agreed to stop childbearing and lowest when both wanted more children. In areas where wives' decision making is limited, family planning is not widespread, and there are differences in husbands' and wives' fertility preferences, as well as reports of substantial clandestine use of contraception (Biddlecom and Fapohunda 1998, Castle et al. 1999). The effect of age cohort (15 - 49 years) on desired fertility behavior reflects socioeconomic, cultural and political contexts of women of their reproductive age (Kishor 1999, 2000 and Jejeebhoy 1995). Studies conducted in Asian countries have shown that women's empowerment is associated with contraceptive use and lower fertility (Jejeebhoy 1995). In the study of Ethiopia, clear evidence is found that women who participate in household decisionmaking are more likely to use contraception (Hogan et al. 1999). Understanding this relationship

*Corresponding author: <nazninalam@gmail.com>. ${ }^{1}$ Department of Business Administration, Stamford University Bangladesh, 51 Siddeswari Road, Dhaka-1217, Bangladesh. 
is imperative in Bangladesh, where fertility remains high. Yet there is also a substantial unfulfilled demand for smaller families among Bangladeshi women. Unmet need for family planning is high in Bangladesh, with $62 \%$ of married women aged 15 - 49 reporting that they do not want to have another child soon or at all, but not using any contraceptive method according to BDHS, 2007 (NIPORT 2009). It is very important to note that, another important factor for measuring fertility is "desire of more children". If a woman has decision-making power then she must be able to control the desire of children in spite of the slaying of her husband or in-laws (Acsadi and Johnson-Acsadi 1990). In a study of Kenya it has been shown that the relationship between women's education and fertility behavior varies from generation-to-generation (Omariba 2003). In the context of Bangladesh this study examined the effect of women's decision-making power index and other control factors on the use of contraception and desire for no more children across 'below 25 ' and 'above 25 ' age cohorts.

\section{Data and Methodology}

The Bangladesh Demographic and Health Survey (BDHS) 2007 data has been used for this study. The 2007 BDHS employs a nationally representative sample that covered the entire population residing in private dwelling units in Bangladesh. As described in NIPORT (2009), the survey was based on a two-stage stratified sample of households with 361 (227 rural and 134 urban) Primary Sampling Units (PSUs) at the first stage. A total of 10,819 households were selected for the sample andit was targeted to interview 11,485 ever-married women aged10 - 49. However, 10996 were interviewed finally with a response rate of 98.4 per cent. This study included 8,611 women in the analyses. 2,385 women were excluded from this study list wise due to having missing values on the study variables.

As BDHS data showed that fertility is completed by age 35, this study divided all women of reproductive age into two different age cohorts: below 25 and above 25 age cohort. In this study we considered two separate outcome variables: use contraceptive and desire no more children. Both outcome variables are a measure of fertility behavior and therefore we tested the effect of women decision-making power index on both outcome variables in two different age cohorts and in pooled sample. The socio-demographic and economic variables were also controlled while investigating such effect. The main exposure variable of this study (decision-making power index of women) is constructed using standard statistical processes consisting of regression technique and factor analysis as explained in detail in following section.

The analysis of data included a description of the study population followed by investigating the associations among all categories of the independent and the dependent variables and finally a binary logistic regression analysis was conducted for each dichotomous dependent variable to find the net effect of decision-making power in two different age cohorts and in pooled sample.

Construction of decision-making power index: The exposure variable of this study is women's decision-making power index. The criteria for defining women's decision-making power index are given by age difference between them and their partners, employment, 
marriage, human capital (education and experience), who in the household has the final say in decisions over visits to friends and family, the household budget, children's and own health (Kishor 2000, Westoff and Ochoa 1991, Smith et al. 2003).

According to Kishor (2000), indicators for measuring women's decision-making power index can be of three types: direct evidence, sources and setting of power. Considering the multidimensionality of the concept of women's decision-making power index. This study used the following indicators to construct decision making power index: (i) Whether women work for cash income, (ii) age at first marriage, (iii) the percent difference in the woman's and her partner's age, (iv) the difference in the woman's and her partner's years of education, (v) final say on making large household purchases, (vi) final say on making household purchases for daily needs(vii) final say on own health care, (viii) final say on child health care and (ix) final say on visits to family or relatives. Indicators (i) and (ii) are source indicators, while (iii) and (iv) are setting indicators, and (v) to (ix) are the direct evidence indicators. All categorical indicators were recoded into dichotomous groups for analysis.

The indicator 'the difference in the woman's and her partner's years of education' was calculated by the following steps: Firstly, the simple difference woman's and her husband's single year of education was taken as follows- 'education difference' $=$ (Education in single years - husband's education in single years). Secondly, in constructing this measure, a substantial number of cases ( 32 per cent) were found where the difference in years of education was zero because both the woman and her husband have zero years of education. It may reveal a weak association between 'education difference' and direct measures of decision-making power, contrary to expectations, when these cases were included. It was hypothesized that the double zero cases actually represent situations where poverty limits all children from attending school, regardless of their gender (either because incomes are low, schools are non-existent, or both). We therefore adjusted 'education difference' by predicting the double zero cases using a regression of 'education difference' on the three other indicators and various other household characteristics as independent variables. As expected, the mean of the adjusted measure $(-0.44)$ dropped considerably from the original $(-0.68)$. The new variable was named as 'adjusted difference in woman's and her partner's year of education'. The independent variables for regression of education difference were: whether women work for cash income, age at first marriage, the per cent difference in the woman's and her partner's age, final say on own health care, final say on child health care, type of place of residence, wealth index factor score and total children ever born. Regression equation for education difference was: $\mathrm{Y}=-0.341+0.069 *$ Age at first marriage $-0.00000672 . *$ Wealth index factor score $-0.528 *$ Total children ever born. This equation was predicted for all double zero cases. After replacing those double zero cases by these predicted values in the 'education difference' variable, we finally have got the indicator 'adjusted difference in woman's and her partner's year of education.

Then factor analysis was employed to combine the nine indicators into an index. The equation for women's decision-making power index was: women's decision-making power 
index $=0.181 *$ whether women work for cash income $+0.044^{*}$ age at marriage $+0.177^{*}$ per cent difference in woman's and her partner's age $-0.044^{*}$ adjusted difference in woman's and her partner's year of education $+0.782 *$ final say on making large household purchases +0.733 * final say on making household purchases for daily needs $+0.691 *$ final say on own health care $+0.773 *$ final say on child health care $+0.705^{*}$ final say on visits to family or relatives +0.258

* goes to health center alone or with kids.

According to NIPORT (2009), the number of decisions that women make themselves or jointly with their husbands is positively related to women's empowerment and reflects the degree of control women are able to exercise in areas that affect their lives and environments. The percentages of married women by the number decisions (number of aspects of direct evidence indicators) made in the household were 27, 24 and 49 for no/one, two/three and four/five, respectively (NIPORT 2009). These facts have been considered in categorizing the obtained factor scores into low/medium/high.

In this process, the factor scores were standardized ( $\mathrm{z}$ - scores) in relation to a normal distribution with a mean of zero and standard deviation of one (Gwatkin et al. 2000) and women were divided into three categories (low, medium and high decision making power index) on the basis of the quintiles of the $\mathrm{z}$ - scores i.e., $27^{\text {th }}$ per centile was the cutting point for low index, $51^{\text {th }}$ per centile was the cutting point for medium index, and the remaining scores for high decision making power index.

\section{Results and Discussion}

The tables for descriptive statistics were not shown for space limitation. Most of the women in all cases (86.7 per cent in 'pooled sample', 83 per cent in 'below 25' age cohort and 88.6 per cent in 'above 25' age cohort) used contraceptives. Also most of the women in 'pooled sample' (70.5 per cent), and in 'above 25 ' age cohort ( 87 per cent) desired no more children. However, in 'below 25' age cohort most of the women (61.6 per cent) desired more children. As our exposure variable was women's decision-making power index, it showed that 27 per cent women had low decision-making power, 24 per cent women's decision-making power was medium and the remaining 49 per cent women had high decision-making power index. In 'below 25 age' cohort the percentages of women for low, medium and high decision-making power index were 47, 25 and 28, respectively. For above 25 age cohort these percentages were 17, 23 and 60, respectively. This showed greater percentage of high decision making power in older cohort and greater percentage of low decision-making power in the younger cohort. This pattern was consistent with BDHS 2007 report (NIPORT 2009).

Percentage distribution of ever-married women aged 15 - 49 years by "use contraceptive" and "desire no more children" are presented in Table 1 and 2, respectively. For all cases women's percentage of using contraception increased with the increasing level of decisionmaking power index. For pooled sample, 'below 25' age cohort and 'above 25' age cohort with low decision-making power $80.4,79.6$ and 81.7 per cent women used contraceptive while 
Impact of decision-making power index on fertility behavior

Table 1. Percentage distribution of ever-married women aged 15 - 49 years "use contraceptive", by some selected socio-economic and demographic characteristics.

\begin{tabular}{|c|c|c|c|c|c|c|c|c|c|}
\hline \multirow[t]{2}{*}{ Variables } & \multicolumn{3}{|c|}{ Pooled sample } & \multicolumn{3}{|c|}{ Below 25} & \multicolumn{3}{|c|}{ Above 25} \\
\hline & No & Yes & $\mathrm{p}$ value & No & Yes & $\mathrm{p}$ value & No & Yes & $\mathrm{p}$ value \\
\hline \multicolumn{10}{|c|}{ Women's decision-making power index } \\
\hline Low & 19.6 & 80.4 & $<0.01$ & 20.4 & 79.6 & $<0.01$ & 18.3 & 81.7 & $<0.01$ \\
\hline Medium & 12.8 & 87.2 & & 15.8 & 84.2 & & 11.2 & 88.8 & \\
\hline High & 10.0 & 90.0 & & 12.3 & 87.7 & & 9.5 & 90.5 & \\
\hline \multicolumn{10}{|l|}{ Women's education } \\
\hline No education & 17.7 & 82.3 & $<0.01$ & 24.8 & 75.2 & $<0.01$ & 16.3 & 83.7 & $<0.0$ \\
\hline Primary & 13.5 & 86.5 & & 20.0 & 80.0 & & 9.8 & 90.2 & 1 \\
\hline Secondary & 10.6 & 89.4 & & 12.9 & 87.1 & & 8.1 & 91.9 & \\
\hline Higher & 6.0 & 94.0 & & 13.2 & 86.8 & & 3.6 & 96.4 & \\
\hline \multicolumn{10}{|l|}{ Husband's education } \\
\hline No education & 17.6 & 82.4 & $<0.01$ & 23.5 & 76.5 & $<0.01$ & 15.3 & 84.7 & $<0.0$ \\
\hline Primary & 13.6 & 86.4 & & 16.6 & 83.4 & & 11.4 & 88.6 & 1 \\
\hline Secondary & 11.3 & 88.7 & & 14.7 & 85.3 & & 9.3 & 90.7 & \\
\hline Higher & 6.8 & 93.2 & & 9.1 & 90.9 & & 6.0 & 94.0 & \\
\hline \multicolumn{10}{|l|}{ Residence } \\
\hline Rural & 16.2 & 83.8 & $<0.01$ & 20.2 & 79.8 & $<0.01$ & 14.1 & 85.9 & $<0.0$ \\
\hline Urban & 8.4 & 91.6 & & 11.0 & 89.0 & & 7.2 & 92.8 & 1 \\
\hline \multicolumn{10}{|c|}{ Number of living children } \\
\hline $0-1$ & 21.8 & 78.2 & $<0.01$ & 20.9 & 79.1 & $<0.01$ & 24.5 & 75.5 & $<0.0$ \\
\hline $2-3$ & 8.9 & 91.1 & & & & & 7.8 & 92.2 & 1 \\
\hline 2 or more & & & & 11.6 & 88.4 & & & & \\
\hline 4 or more & 13.2 & 86.8 & & & & & 13.4 & 86.6 & \\
\hline \multicolumn{10}{|l|}{ Women's occupation } \\
\hline Unemployed & 15.4 & 84.6 & $<0.01$ & 19.0 & 81.0 & $<0.01$ & 13.3 & 86.7 & $<0.0$ \\
\hline Agriculture/labor & 9.1 & 90.9 & & 11.0 & 89.0 & & 8.3 & 91.7 & 1 \\
\hline Professional/business & 5.1 & 94.9 & & 9.6 & 90.4 & & 4.2 & 95.8 & \\
\hline \multicolumn{10}{|l|}{ Wealth index } \\
\hline Poorest & 16.6 & 83.4 & $<0.01$ & 20.2 & 79.8 & $<0.01$ & 14.8 & 85.2 & $<0.0$ \\
\hline Poorer & 15.6 & 84.4 & & 20.2 & 79.8 & & 12.9 & 87.1 & 1 \\
\hline Middle & 14.5 & 85.5 & & 17.7 & 82.3 & & 12.7 & 87.3 & \\
\hline Richer & 12.5 & 87.5 & & 16.8 & 83.2 & & 10.1 & 89.9 & \\
\hline Richest & 9.3 & 90.7 & & 11.2 & 88.8 & & 8.6 & 91.4 & \\
\hline \multicolumn{10}{|l|}{ Division } \\
\hline Barisal & 8.1 & 91.9 & $<0.01$ & 9.4 & 90.6 & $<0.01$ & 7.5 & 92.5 & $<0.0$ \\
\hline Chittagong & 19.6 & 80.4 & & 25.4 & 74.6 & & 16.3 & 83.7 & 1 \\
\hline Dhaka & 10.1 & 89.9 & & 12.5 & 87.5 & & 8.9 & 91.1 & \\
\hline Khulna & 4.7 & 95.3 & & 6.3 & 93.7 & & 3.9 & 96.1 & \\
\hline Rajshahi & 5.8 & 94.2 & & 7.9 & 92.1 & & 4.7 & 95.3 & \\
\hline Sylhet & 36.9 & 63.1 & & 46.1 & 53.9 & & 32.2 & 67.8 & \\
\hline \multicolumn{10}{|l|}{ Religious affiliation } \\
\hline Non-muslim & 10.1 & 89.9 & $<0.01$ & 16.1 & 83.9 & 0.362 & 7.3 & 92.7 & $<0.0$ \\
\hline Muslim & 13.7 & 86.3 & & 17.1 & 82.9 & & 11.9 & 88.1 & 1 \\
\hline \multicolumn{10}{|l|}{ Age at marriage } \\
\hline Less than 18 & 13.0 & 87.0 & $<0.01$ & 15.9 & 84.1 & $<0.01$ & 11.4 & 88.6 & 0.963 \\
\hline 18 and above & 14.8 & 85.2 & & 22.8 & 77.2 & & 11.4 & 88.6 & \\
\hline
\end{tabular}


Table 2. Percentage distribution of ever-married women aged 15 - 49 years "desire no more children", by some selected socio-economic and demographic characteristics.

\begin{tabular}{|c|c|c|c|c|c|c|c|c|c|}
\hline \multirow[t]{2}{*}{ Variables } & \multicolumn{3}{|c|}{ Pooled sample } & \multicolumn{3}{|c|}{ Below 25} & \multicolumn{3}{|c|}{ Above 25} \\
\hline & No & Yes & $\bar{p}$ value & No & Yes & $\mathrm{p}$ value & No & Yes & $\mathrm{p}$ value \\
\hline \multicolumn{10}{|c|}{ Women's decision-making power index } \\
\hline Low & 43.3 & 56.7 & \multirow[t]{3}{*}{$<0.01$} & 63.7 & 36.3 & \multirow[t]{3}{*}{$<0.05$} & 14.1 & 85.9 & \multirow[t]{3}{*}{0.568} \\
\hline Medium & 28.9 & 71.1 & & 57.7 & 42.3 & & 12.7 & 87.3 & \\
\hline High & 22.1 & 77.9 & & 61.4 & 38.6 & & 12.8 & 87.2 & \\
\hline \multicolumn{10}{|l|}{ Women's education } \\
\hline No education & 15.0 & 85.0 & \multirow[t]{4}{*}{$<0.01$} & 46.3 & 53.7 & \multirow[t]{4}{*}{$<0.01$} & 8.6 & 91.4 & \multirow[t]{4}{*}{$<0.01$} \\
\hline Primary & 28.4 & 71.6 & & 58.6 & 41.4 & & 11.7 & 88.3 & \\
\hline Secondary & 42.8 & 57.2 & & 66.7 & 33.3 & & 17.1 & 82.9 & \\
\hline Higher & 39.5 & 60.5 & & 77.2 & 22.8 & & 26.8 & 73.2 & \\
\hline \multicolumn{10}{|l|}{ Husband's education } \\
\hline No education & 22.5 & 77.5 & \multirow[t]{4}{*}{$<0.01$} & 54.9 & 45.1 & \multirow[t]{4}{*}{$<0.01$} & 9.9 & 90.1 & \multirow[t]{4}{*}{$<0.01$} \\
\hline Primary & 31.8 & 68.2 & & 59.2 & 40.8 & & 12.9 & 87.1 & \\
\hline Secondary & 33.3 & 66.7 & & 66.6 & 33.4 & & 12.7 & 87.3 & \\
\hline Higher & 34.2 & 65.8 & & 70.5 & 29.5 & & 20.6 & 79.4 & \\
\hline \multicolumn{10}{|l|}{ Residence } \\
\hline Rural & 30.6 & 69.4 & \multirow[t]{2}{*}{$<0.01$} & 62.7 & 37.3 & \multirow[t]{2}{*}{$<0.05$} & 12.8 & 87.2 & \multirow[t]{2}{*}{0.302} \\
\hline Urban & 27.7 & 72.3 & & 59.4 & 40.6 & & 13.3 & 86.7 & \\
\hline \multicolumn{10}{|c|}{ Number of living children } \\
\hline $0-1$ & 79.8 & 20.2 & $<0.01$ & 84.8 & 15.2 & $<0.01$ & 63.9 & 36.1 & $<0.01$ \\
\hline $2-3$ & 17.0 & 83.0 & & & & & 11.9 & 88.1 & \\
\hline 2 or more & & & & 29.3 & 70.7 & & & & \\
\hline 4 or more & 2.1 & 97.9 & & & & & 2.0 & 98.0 & \\
\hline Women's occupation & & & & & & & & & \\
\hline Unemployed & 32.4 & 67.6 & $<0.01$ & 64.4 & 35.6 & $<0.01$ & 13.6 & 86.4 & 0.131 \\
\hline Agriculture/labor & 23.4 & 76.6 & & 52.7 & 47.3 & & 11.6 & 88.4 & \\
\hline Professional/business & 20.9 & 79.1 & & 57.7 & 42.3 & & 13.6 & 86.4 & \\
\hline Wealth index & & & & & & & & & \\
\hline Poorest & 25.3 & 74.7 & $<0.01$ & 52.8 & 47.2 & $<0.01$ & 10.9 & 89.1 & $<0.01$ \\
\hline Poorer & 29.0 & 71.0 & & 57.5 & 42.5 & & 11.8 & 88.2 & \\
\hline Middle & 30.7 & 69.3 & & 65.3 & 34.7 & & 11.4 & 88.6 & \\
\hline Richer & 32.0 & 68.0 & & 65.2 & 34.8 & & 13.0 & 87.0 & \\
\hline Richest & 29.7 & 70.3 & & 65.0 & 35.0 & & 16.0 & 84.0 & \\
\hline Division & & & & & & & & & \\
\hline Barisal & 30.7 & 69.3 & $<0.01$ & 65.3 & 34.7 & $<0.05$ & 12.7 & 87.3 & $<0.01$ \\
\hline Chittagong & 31.9 & 68.1 & & 63.3 & 36.7 & & 14.2 & 85.8 & \\
\hline Dhaka & 28.5 & 71.5 & & 61.2 & 38.8 & & 12.5 & 87.5 & \\
\hline Khulna & 26.8 & 73.2 & & 58.7 & 41.3 & & 11.5 & 88.5 & \\
\hline Rajshahi & 25.8 & 74.2 & & 56.4 & 43.6 & & 9.9 & 90.1 & \\
\hline Sylhet & 35.2 & 64.8 & & 66.5 & 33.5 & & 19.1 & 80.9 & \\
\hline Religious affiliation & & & & & & & & & \\
\hline Non-muslim & 29.8 & 70.2 & 0.442 & 66.1 & 33.9 & $<0.10$ & 12.5 & 87.5 & 0.379 \\
\hline Muslim & 29.5 & 70.5 & & 61.1 & 38.9 & & 13.1 & 86.9 & \\
\hline Age at marriage & & & & & & & & & \\
\hline Less than 18 & 26.6 & 73.4 & $<0.01$ & 58.6 & 41.4 & $<0.01$ & 9.5 & 90.5 & $<0.01$ \\
\hline 18 and above & 41.8 & 58.2 & & 76.3 & 23.7 & & 27.0 & 73.0 & \\
\hline
\end{tabular}


for medium, it was $87.2,84.2$ and 88.8 per cent and for high it was $90,87.7$ and 90.5 per cent respectively. Women's percentage of using contraception increased with the increasing level of their or their partner's education in the pooled sample, 'below 25' age cohort and 'above 25 ' age cohort. For all cases, percentage of women who used contraceptive was higher for urban area than that of rural area. With increasing number of living children, the percentages of using contraception increased in 'below 25' age cohort. For women with 0 - 1 living children the percentages of using contraception was 79.1 and for women with 2 or more living children this percentage was 88.4 in this younger cohort. With increasing number of living children, the percentages of using contraception showed different pattern in the 'above 25' age cohort and also in the pooled sample. With 0 - 1 living children woman's percentages of using contraception were 75.5, with 2 - 3 living children those were 92.2 while for women with 4 or more living children those were 86.6 in the 'above 25 ' age cohort. In the pooled sample, the percentages of contraception use were 78.2, 91.1 and 86.8 for women with $0-1,2-3$ and 4 or more living children, respectively. In pooled sample, 'below 25' age cohort and 'above 25 ' age cohort the percentages of using contraception increased with varying respondent occupations. Also in all cases, the women contraceptive use percentage increased as the household wealth index varies from poorest, poorer, middle, richer to richest. The women uses of contraception have significant association with division. Non-muslim was most contraceptive users than the muslim women in pooled sample and 'above 25 ' age cohort while for the 'below 25 ' age cohort the association between religious affiliation and contraceptive use was insignificant. Women whose age at marriage less than 18 were most contraceptive users than whose age at marriage 18 or above in both pooled sample and below 25 age cohort while for the 'above 25 ' age cohort the association between age at marriage and contraceptive use was insignificant.

With increasing level of decision-making power index, the percentages of women 'desire no more children' showed different nature. For women in pooled sample the percentages of childbearing cessation were 56.7, 71.1 and 77.9 with low, medium and high decision-making power index, respectively; for women in 'below 25' age cohort childbearing cessation percentage was most (42.3) whose decision-making power index is medium followed by high (38.6) and low (36.3) decision-making power index; while for the 'above 25' age cohort the association between decision-making power index and childbearing cessation was insignificant. Women's percentage of childbearing cessation decreased with the increasing level of their or their partner's education in the pooled sample, 'below 25' age cohort and 'above 25' age cohort. In 'pooled sample' and 'below 25' age cohort, women percentage for 'desire no more children' was higher for urban area than the rural area; while for the 'above 25' age cohort the association between residence and childbearing cessation was insignificant. For all cases, woman's percentage of childbearing cessation increased with increasing number of living children. Woman's occupation was significantly associated with childbearing cessation in 'pooled sample' and 'below 25' age cohort while for the 'above 25' age cohort this association was insignificant. Household wealth index was significantly associated with childbearing cessation in all cases. 
The women childbearing cessations had significant association with divisions. Religious affiliation was significantly associated with childbearing cessation in the 'below 25 ' age cohort while for the 'pooled sample' and 'above 25 ' age cohort this association was insignificant. In all cases, the percentage of women 'desire no more children' was higher whose age at marriage was less than 18 than whose age at marriage was 18 and above.

Estimated odds ratios from logistic regressions of contraceptive use on socio-demographic variables are demonstrated in Table 3. The results from the pooled sample indicated that as compared to women with low decision-making power, women with high decision-making power were more likely to use contraceptive $(\mathrm{OR}=1.263, \mathrm{p}<0.01)$. Similar effects for high decisionmaking power index were also found in case of the below 25 women cohort (OR $=1.389, \mathrm{p}<$ $0.05)$ and for above 25 women cohort $(\mathrm{OR}=1.43, \mathrm{p}<0.01)$. Additionally, women aged above 25 with medium decision-making power were found to be more intended to use contraceptive $(\mathrm{OR}=1.34, \mathrm{p}<0.05)$ than the women having low decision making power. In both the pooled sample and above 25 women cohorts, higher likelihood of using contraception was found with increasing education level. The odd ratios in favor of using contraception for women in pooled sample with primary, secondary and higher education were estimated as 1.402; $\mathrm{p}<0.01,2.221$; $\mathrm{p}<0.01,2.569 ; \mathrm{p}<0.01$, respectively when compared to women with no education. The similar odd ratios for women in above 25 cohort were found to be 1.582; $<<0.01,2.203 ; \mathrm{p}<0.01$, $5.759 ; \mathrm{p}<0.01$. However, in case of the below 25 cohort, the effect of women's education on their contraceptive use behavior were found to be little different than the others. Though the below 25 women with secondary education were more likely to use contraceptive ( $\mathrm{OR}=1.671$; $\mathrm{p}<0.01)$ than women with primary and no education, the same was not pronounced for women with higher education. Higher levels of husband's education ensured more likelihood of contraceptive use compared to not educated in both the pooled sample (OR $=1.359 ; \mathrm{p}<0.01$ for primary education, $\mathrm{OR}=1.329 ; \mathrm{p}<0.01$ for secondary education and $\mathrm{OR}=1.480 ; \mathrm{p}<0.01$ for higher education) and below 25 women cohorts $(\mathrm{OR}=1.472 ; \mathrm{p}<0.01$ for primary education, $\mathrm{OR}=1.524 ; \mathrm{p}<0.05$ for secondary education and $\mathrm{OR}=2.468 ; \mathrm{p}<0.01$ for higher education). Though the primary educated husbands played significant role to increase contraceptive use (OR $=1.270 ; \mathrm{p}<0.05)$ in case of above 25 women cohort, the other levels of husband's education failed to find such impact as compared to no education. The women living in urban area were more likely to use contraceptive than the rural women in all cases $(\mathrm{OR}=1.914 ; \mathrm{p}<0.01$ in pooled sample, $\mathrm{OR}=1.697 ; \mathrm{p}<0.01$ in below 25 cohort and $\mathrm{OR}=2.099 ; \mathrm{p}<0.01$ in above 25 cohort). As the number of living children increased, the likelihood of contraceptive use was observed to increase in all cohorts. The odds ratios in favor of using contraception for women employed as agricultural worker/labor and employed in professional service/business, were estimated as $1.350 ; \mathrm{p}<0.01,1.913 ; \mathrm{p}<0.05$ respectively when compared to unemployed women in the pooled sample. The similar odds ratios for women in above 25 cohort were found to be 1.341; $p<0.05,2.038 ; \mathrm{p}<0.05$. However, in case of the below 25 cohort, the effect of women's occupation on their contraceptive use behavior were not found as pronounced as the 
Table 3. Logistic model results of the odds ratio for "use contraceptive".

\begin{tabular}{|c|c|c|c|}
\hline Variables & Pooled sample & Below 25 & Above 25 \\
\hline \multicolumn{4}{|c|}{ Women's decision-making power index } \\
\hline \multicolumn{4}{|c|}{ Low $(\mathrm{RC})$} \\
\hline Medium & 1.101 & 0.945 & $1.340 * *$ \\
\hline High & $1.263 * * *$ & $1.389 * *$ & $1.430 * * *$ \\
\hline \multicolumn{4}{|l|}{ Wife's education } \\
\hline \multicolumn{4}{|l|}{ No education (RC) } \\
\hline Primary & $1.402 * * *$ & 1.052 & $1.582 * * *$ \\
\hline Secondary & $2.221 * * *$ & $1.671 * * *$ & $2.203 * * *$ \\
\hline Higher & $2.569 * * *$ & 0.947 & $5.759 * * *$ \\
\hline \multicolumn{4}{|l|}{ Husband's education } \\
\hline \multicolumn{4}{|l|}{ No education $(\mathrm{RC})$} \\
\hline Primary & $1.359 * * *$ & $1.472 * * *$ & $1.270 * *$ \\
\hline Secondary & $1.329 * * *$ & $1.524 * *$ & 1.239 \\
\hline Higher & $1.480 * *$ & $2.468 * * *$ & 1.121 \\
\hline \multicolumn{4}{|l|}{ Residence } \\
\hline \multicolumn{4}{|l|}{ Rural (RC) } \\
\hline Urban & $1.914 * * *$ & $1.697 * * *$ & $2.099 * * *$ \\
\hline \multicolumn{4}{|c|}{ Number of living children } \\
\hline \multicolumn{4}{|c|}{$0-1(\mathrm{RC})$} \\
\hline $2-3$ & $3.680 * * *$ & & $5.927 * * *$ \\
\hline 2 or more & & $3.187 * * *$ & \\
\hline 4 or more & $4.364 * * *$ & & $6.754 * * *$ \\
\hline \multicolumn{4}{|l|}{ Wife's occupation } \\
\hline \multicolumn{4}{|l|}{ Unemployed (RC) } \\
\hline Agriculture/labor & $1.350 * * *$ & $1.402 * *$ & $1.341 * *$ \\
\hline Professional/business & $1.913 * *$ & 1.761 & $2.038^{* *}$ \\
\hline \multicolumn{4}{|l|}{ Wealth index } \\
\hline \multicolumn{4}{|l|}{ Poorest (RC) } \\
\hline Poorer & 1.096 & 1.082 & 1.136 \\
\hline Middle & 1.170 & $1.431 *$ & 1.049 \\
\hline Richer & 1.212 & $1.397 *$ & 1.166 \\
\hline Richest & $1.255^{*}$ & $2.041 * * *$ & 1.005 \\
\hline \multicolumn{4}{|l|}{ Division } \\
\hline Barisal & $6.873 * * *$ & $8.855 * * *$ & $5.743 * * *$ \\
\hline Chittagong & $2.233 * * *$ & $2.162 * * *$ & $2.153 * * *$ \\
\hline Dhaka & $5.002 * * *$ & $5.284 * * *$ & $4.614 * * *$ \\
\hline Khulna & $12.506^{* * *}$ & $12.626^{* * *}$ & $12.794 * * *$ \\
\hline Rajshahi & $10.418^{* * *}$ & $10.666^{* * *}$ & $10.266^{* * *}$ \\
\hline \multicolumn{4}{|l|}{ Sylhet (RC) } \\
\hline \multicolumn{4}{|l|}{ Religious affiliation } \\
\hline Non-muslim & $1.863 * * *$ & - & $2.207 * * *$ \\
\hline \multicolumn{4}{|l|}{ Muslim (RC) } \\
\hline \multicolumn{4}{|l|}{ Age at marriage } \\
\hline Less than 18 & 1.054 & $1.335^{*}$ & - \\
\hline \multicolumn{4}{|l|}{18 and above (RC) } \\
\hline -2 Log likelihood & 5523.165 & 2163.825 & 3305.747 \\
\hline Chi square (df) & $1231.484(24)^{* * *}$ & $505.113(22)^{* * *}$ & 728.415 \\
\hline & & & $(23)^{* * *}$ \\
\hline Sample size & 8611 & 2924 & 5687 \\
\hline
\end{tabular}

$\mathrm{RC}=$ Reference category, ${ }^{* * *} \mathrm{p}<0.01,{ }^{* *} \mathrm{p}<0.05, * \mathrm{p}<0.1$. 
other two cohorts. Though the below 25 women employed as agricultural worker/labor were more likely to use contraceptive $(\mathrm{OR}=1.402 ; \mathrm{p}<0.05)$ than the unemployed women, the same effect was not found statistically significant for women employed in professional service/business. The impact of household wealth was found to increase contraceptive use significantly among the below 25 women but the same effect was not statistically significant for above 25 women. The household wealth impact on contraceptive use in the pooled sample was also found in favor of increasing likelihood of contraceptive use but was not as apparent as the below 25 women cohort. In all the cohorts, it was found that the women in Sylhet division were significantly less likely to use contraceptive than the other divisions. The non-muslim women were found to be more likely to use contraceptive than the muslims in both pooled sample and above 25 women cohorts while such association was statistically insignificant in below 25 women cohort. Age at marriage of the women was a significant determinant of contraceptive use among the below 25 women only and the effect was found to increase likelihood of contraceptive use compared to women married at 18 years or above ages.

Table 4 presents the estimated odds ratios in favor of desire no more children from logistic regressions on socio-demographic variables. As the bivariate analysis demonstrated no significant association between women decision making power index (the exposure variable of this research) and the desire no more children, the logistic regression was not estimated for this cohort. After adjusting for socio-demographic characteristics, women's exposure to higher decision-0making power indicated significantly lower desire for more children in the pooled sample $(\mathrm{OR}=1.217 ; \mathrm{p}<0.05$ for medium exposure and $\mathrm{OR}=1.398 ; \mathrm{p}<0.01$ for high exposure). However, these effects were not statistically significant for below 25 women. Among the socio-demographic factors, women's education, residence, number of living children, women's occupation, division showed significant influence to determine the desire for more children in both pooled and below 25 cohorts. One of the interesting findings of this study was that both in pooled sample and below 25 cohorts, educated women were more likely to desire children than women with no education. From the pooled sample, the bivariate analysis of education levels and ideal number of children (ideal number achieved vs not achieved) also revealed the same pattern. In no education category, the percentage of women required achieving ideal number of children was 17.4, whereas this percentage was 29.0, 43.0 and 40.0 in primary, secondary and higher education categories, respectively. The association between the education level and ideal number of children was found to be statistically significant $(p<0.01)$. The same fact also found in below 25 age cohort.

The urban women were found to be more likely to cease child-bearing than the rural women in both cohorts. As the number of living children increased, the likelihood of being desired for more children was observed to decrease in both cohorts. The likelihood of having no desire for more children was significantly higher among all types (agriculture/labor and professional/ business) of employed women than the unemployed in pooled sample. The similar effect on desire for more children was also identified for women working as agricultural worker/labor 
Impact of decision-making power index on fertility behavior

Table 4. Logistic model results of the odds ratio for "desire no more children".

\begin{tabular}{|c|c|c|}
\hline Variables & Pooled sample & Below 25 \\
\hline \multicolumn{3}{|c|}{ Women's decision-making power index } \\
\hline \multicolumn{3}{|c|}{ Low $(\mathrm{RC})$} \\
\hline Medium & $1.217 * *$ & 1.098 \\
\hline High & $1.398 * * *$ & 0.961 \\
\hline \multicolumn{3}{|l|}{ Wife's education } \\
\hline \multicolumn{3}{|l|}{ No education (RC) } \\
\hline Primary & $0.548 * * *$ & $0.641 * * *$ \\
\hline Secondary & $0.495 * * *$ & $0.686^{* *}$ \\
\hline Higher & $0.516 * * *$ & $0.589 *$ \\
\hline \multicolumn{3}{|l|}{ Husband's education } \\
\hline \multicolumn{3}{|l|}{ No education (RC) } \\
\hline Primary & 0.955 & 1.093 \\
\hline Secondary & 1.149 & 1.132 \\
\hline Higher & 1.158 & 1.038 \\
\hline \multicolumn{3}{|l|}{ Residence } \\
\hline \multicolumn{3}{|l|}{ Rural (RC) } \\
\hline Urban & $1.286 * * *$ & $1.231^{*}$ \\
\hline \multicolumn{3}{|c|}{ Number of living children } \\
\hline \multicolumn{3}{|c|}{$0-1(\mathrm{RC})$} \\
\hline $2-3$ & $20.074 * * *$ & \\
\hline 2 or more & & $14.950 * * *$ \\
\hline 4 or more & $220.034 * * *$ & \\
\hline \multicolumn{3}{|l|}{ Wife's occupation } \\
\hline \multicolumn{3}{|l|}{ Unemployed (RC) } \\
\hline Agriculture/labor & $1.193 * *$ & $1.324 * *$ \\
\hline Professional/business & $1.853 * * *$ & 1.071 \\
\hline \multicolumn{3}{|l|}{ Wealth index } \\
\hline \multicolumn{3}{|l|}{ Poorest (RC) } \\
\hline Poorer & 1.107 & 1.004 \\
\hline Middle & 1.110 & 0.793 \\
\hline Richer & $1.317 * *$ & 1.046 \\
\hline Richest & $1.757 * * *$ & 1.170 \\
\hline \multicolumn{3}{|l|}{ Division } \\
\hline Barisal & $2.456 * * *$ & 1.307 \\
\hline Chittagong & $1.600 * * *$ & $1.435^{* *}$ \\
\hline Dhaka & $1.976 * * *$ & $1.364^{*}$ \\
\hline Khulna & $3.647 * * *$ & $2.550 * * *$ \\
\hline Rajshahi & $3.812 * * *$ & $2.607 * * *$ \\
\hline \multicolumn{3}{|l|}{ Sylhet (RC) } \\
\hline \multicolumn{3}{|l|}{ Religious affiliation } \\
\hline Non-muslim & - & 1.058 \\
\hline \multicolumn{3}{|l|}{ Muslim (RC) } \\
\hline \multicolumn{3}{|l|}{ Age at marriage } \\
\hline Less than 18 & 1.151 & 1.070 \\
\hline \multicolumn{3}{|l|}{18 and above (RC) } \\
\hline-2 log likelihood & 6169.55 & 2847.175 \\
\hline Chi square (df) & $4276.34(23)^{* * *}$ & $1048.642(23)^{* * *}$ \\
\hline Sample size & 8611 & 2924 \\
\hline
\end{tabular}

$\mathrm{RC}=$ Reference category, ${ }^{* * *} \mathrm{p}<0.01,{ }^{* *} \mathrm{p}<0.05,{ }^{*} \mathrm{p}<0.1$. 
in the below 25 cohort. However, in the same cohort, women who were in professional service/business were not statistically different from unemployed women in such desire. The household wealth did not find any significant influence in explaining childbearing cessation of women aged below 25 though in the pooled sample richer and richest women were found to be more likely to cease childbearing than the women with lower household wealth. In both the pooled and below 25 cohorts, it was found that the women in Sylhet division were significantly less likely to stop child, bearing than the other divisions. The factors religion and women's age at marriage did not carry significant effect on deciding women's childbearing in any of the pooled and below 25 cohorts.

\section{References}

Acsadi, G.T.F. and G. Johnson-Acsadi.1990. Demand for Children and Child Spacing. In: Population growth and reproduction in sub-Saharan Africa: Technical analyses of fertility and its consequences, Acsadi, G.T., F.G. Johnson-Acsadi and R.A. Bulatao (eds.). Washington D. C.: The World Bank.

Bankole A and Singh S. 1998. Couple's fertility and contraceptive decision-making in developing countries: hearing the man's voice. International Family Planning Perspectives 24(1): 15-24.

Biddlecom AE and Fapohunda BM. 1998. Covert contraceptive use: Prevalence, motivations, and consequences. Studies in Family Planning 29(4): 360-372.

Blanc A.K. 2001. The effect of power in sexual relationships on sexual and reproductive health: An examination of the evidence. Studies inFamily Planning 32(3): 189-213.

Castle, S. and Konate, M.K. 1999. A qualitative study of clandestine contraceptive use in urban Mali. Studies in Family Planning 30(3): 231-248.

Govindasamy P. and Malhotra A. 1996. Women's position and family planning in Egypt. Studies in Family Planning 27(6): 328-340.

Gwatkin, D.R., S. Rutstein, K. Johnson, R.P. Pande, and A. Wagstaff. 2000. Socio-economic Differences in Health, Nutrition and Poverty. HNP/Poverty Thematic Group of the World Bank.Washington, D.C., The World Bank.

Hogan, D.P., Berhanu B. and Hailemariam A. 1999. Household Organization, Women's Autonomy, and Contraceptive Behavior in Southern Ethiopia. Studies in Family Planning. 30.

Jejeebhoy, S. 1995. Women's Education, Autonomy and Reproductive Behavior: Experience from developing countries. Oxford: Clarendon Press.

Kishor, S. 1999. Women's Empowerment and Contraceptive Use in Egypt. Paper presented at the Annual Meetings of the Population Association of America, New York.

Kishor, S. 2000. Women's Contraceptive Use in Egypt: What do Direct Measures of Empowerment Tell Us? Paper presented at the 2000 Annual meeting of the Population Association of America, Los Angeles, California.

Mai Do and Nami Kurimoto. 2012. Women's Empowerment and Choice of Contraceptive Methods in Selected African Countries. International Perspectives on Sexual and Reproductive Health 38(1): 2333.

NIPORT, Mitra and Associates, and Macro International. 2009. Bangladesh Demographic and Health Survey 2007. Dhaka, Bangladesh and Calverton, Maryland, USA. 
Impact of decision-making power index on fertility behavior

Omariba, W.R. 2003. Women's Educational Attainment and Intergenerational Pattern of Fertility Behavior in Kenya. Population Studies Centre. London, CANADA N6A 5C2.

Smith L. C., U. Ramakrishnan, A. Ndiaye, L. Haddad, and R. Martorell. 2003. The Importance of Women's Status for Child Nutrition in Developing Countries. Research Report 3. International Food Policy Research Institute, Washington DC, Department of International Health, Emory University.

Westoff, C.F. and L.H. Ochoa. 1991. Unmet Need and the Demand for Family Planning.Comparative studies.Demographic and Health Surveys.Institute for Resource Development/Macro International Inc. Columbia Maryland, USA.

(Manuscript received on received on 26 February, 2013; revised on 12 June, 2013) 